\title{
Electrophysiological localization of ulnar nerve lesions
}

\author{
J. P A Y A N ${ }^{1}$ \\ From the Laboratory of Clinical Neurophysiology, University Hospital, Copenhagen, Denmark
}

An affection of the ulnar nerve is not difficult to diagnose but may be difficult to localize. The study of peripheral nerve conduction velocity was brought to bear upon this problem by Simpson (1956), who found distal slowing in motor fibres in a deep palmar lesion of the ulnar nerve and local slowing in a chronic traumatic lesion at the elbow. Sensory conduction in clinically established lesions of the ulnar nerve at the elbow was investigated by Gilliatt and Thomas (1960); in none of nine could a sensory action potential be recorded at the wrist or a mixed nerve potential proximal to the elbow. Kaeser (1963), also using surface recording electrodes, found that when there was a lesion of the nerve at the elbow the sensory potential at the wrist was absent or too small to use for measurement. He was nevertheless able to localize 25 out of 29 lesions at the elbow by stimulating the nerve proximal and distal to the joint and demonstrating slowed motor conduction in the affected segment. Our experience of motor conduction studies was less favourable, and, since technical improvements now permit the investigation of sensory conduction, we decided to re-evaluate the means by which lesions of the ulnar nerve may be diagnosed and localized.

\section{PATIENTS AND NORMAL SUBJECTS}

Lesions of 50 ulnar nerves (29 right, 21 left) were studied in 46 patients, 37 of whom were men. Nine patients were aged below 40 years, 34 were from 40 to 70 and three were above 70 . The history was taken and the clinical examination conducted according to the scheme of Table I.

AETIOLOGy (Table II) Three-quarters of the lesions fell into three groups, of which the largest comprised those without relevant history.

SYMPTOMS (Table III) In three-quarters of the lesions the symptoms had lasted for a year or less; two-thirds gave rise to both sensory and motor symptoms.

1Supported by a scholarship from the Danish Ministry of Education. Present address: Depaitment of Neurophysiology, Hospital for Sick Children, Great Ormond Street, London.
TABLE I

SCHEME FOR COLLECTION OF CLINICAL DATA

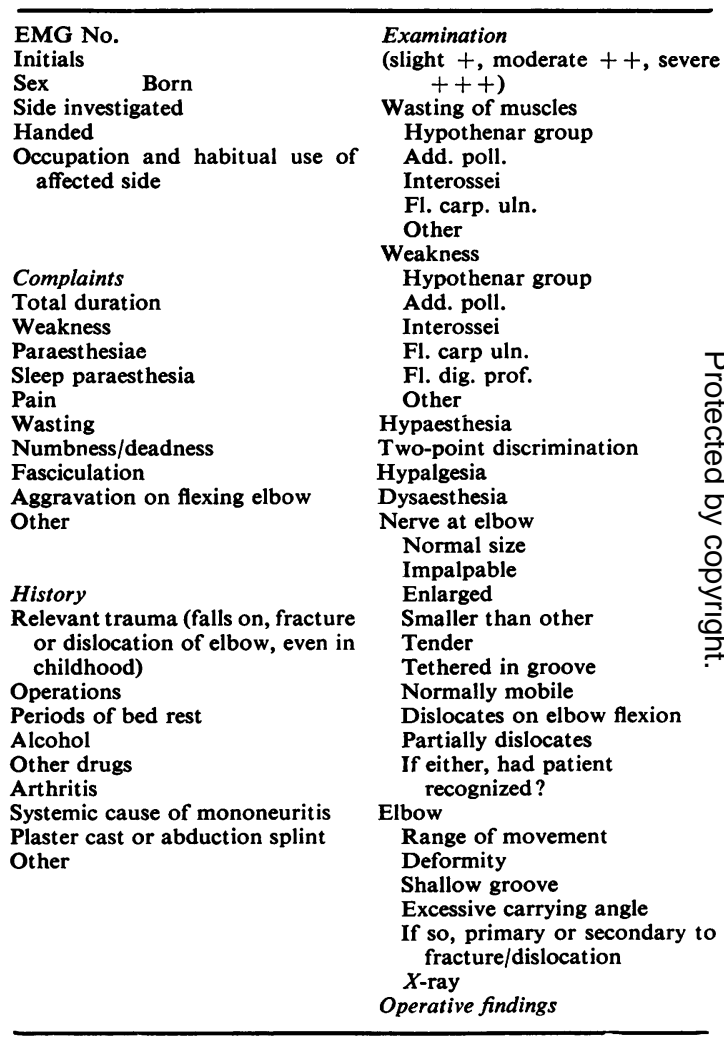

PHYSICAL SIGNS (Table III) Using McGowan's (1950) grading of severity, seven lesions fell into Grade I (minimal lesions with no detectable motor weakness of the hand), 36 into Grade II (intermediate lesions) and seven into Grade III (severe lesions, with paralysis of one or more of the ulnar intrinsic muscles). On clinical grounds 13 lesions could be localized to the elbow and none to the wrist or hand.

ASYMPTOMATIC LESIONS When the contralateral ulnar nerve was investigated to provide a control the 
TABLE II

\section{AETIOLOGY}

\begin{tabular}{|c|c|c|}
\hline Aetiology & No. & $\%$ of total \\
\hline Unknown & 19 & 38 \\
\hline $\begin{array}{l}\text { Compression during uncorisciousness } \\
\text { general anaesthesia ( } 8 \text { ) } \\
\text { other (3) }\end{array}$ & 11 & 22 \\
\hline $\begin{array}{l}\text { Trauma to the elbow region } \\
\text { acute (7) } \\
\text { chronic (1) }\end{array}$ & 8 & 16 \\
\hline Bed rest & 5 & 10 \\
\hline Mechanical abnormality of elbow joint & 4 & 8 \\
\hline $\begin{array}{l}\text { Miscellaneous } \\
\text { polyneuropathy (1) } \\
\text { post-inoculation } \\
\text { (anti-tetanus) (1) } \\
\text { plaster cast (1) }\end{array}$ & 3 & 6 \\
\hline Total & 50 & 100 \\
\hline
\end{tabular}

TABLE III

SYMPTOMS AND SIGNS

\begin{tabular}{lr}
\hline Symptoms & \\
\hline Duration (yr) & \\
One or less & 38 \\
One to five & 9 \\
More than five & 3 \\
Sensory and motor & 33 \\
Sensory only & 12 \\
Motor only & 3 \\
Uncertain & 2 \\
\hline Physical signs & \\
Sensory and motor & 38 \\
Sensory only & 7 \\
Motor only & 41 \\
Neither sensory nor motor & 1 \\
Involvement of forearm muscles & 7 \\
Abnormal two point discrimination (31 cases tested) & 14 \\
Raised sensory threshold & 27 \\
Spontaneous dislocation of nerve on elbow flexion & \\
partial & 8 \\
complete & 2 \\
Mechanical abnormality of elbow & 4 \\
\hline
\end{tabular}

'One of these patients was confused and may have had hypaesthesia also.

first three patients proved to have electrophysiological abnormalities on the clinically normal side, judging by the values obtained in volunteers. Since childhood one patient (case $28 \mathrm{R}$, Table $\mathrm{X}$ ) had been able to provoke paraesthesiae by leaning on the elbow. The lesions for which these patients had been referred were in two cases spontaneous-that is, without relevant history-and in the third secondary to an old infective arthritis.

NORMAL SUBJECTS Sensory and motor conduction were investigated in 36 volunteers from three age groups, 18 to 32,40 to 65 , and 70 to 89 years.

\section{METHOD}

As most lesions of the ulnar nerve occur in or near the cubital sulcus the best chance of localizing them seems likely to come from studying that segment of the nerve which traverses the elbow region and comparing it with neighbouring segments. Accordingly, the electrophysiological investigation comprised the study of sensory and motor conduction with electrodes positioned proximal and distal to the elbow, at the wrist and sometimes in the axilla. In a number of cases, furthermore, electromyography of different ulnar-innervated hand muscles was performed to see whether it contributed to diagnosis or localization.

The patient lay supine with the arm at $45^{\circ}$ to the trunk, the elbow extended and the forearm supinated. The limb was warmed before and throughout the investigation and the temperature measured by a thermocouple on the skin and near the nerve. At each recording site the temperature near the nerve was 34 to $36^{\circ} \mathrm{C}$.

1. SENSORY The electrodes were stainless steel needles $0.6 \mathrm{~mm}$ in diameter, insulated except at the tip. They were placed at the wrist, about $5 \mathrm{~cm}$ distal to the medial epicondyle ('below-sulcus'), about $5 \mathrm{~cm}$ proximal to it ('above-sulcus') and, in 10 cases, about $15 \mathrm{~cm}$ proximal to it ('axilla'). The stigmatic electrode ( $3 \mathrm{~mm}$ bared tip) was placed close to the nerve by adjusting its position until the lowest threshold for the potential evoked in an hypothenar muscle was reached when the electrode was used to stimulate the nerve $(<1 \mathrm{~mA})$. When no muscle action potential could be evoked the electrode had to be placed blindly at wrist and below-sulcus, but it was always possible to place the electrode proximal to the sulcus by using the potential evoked in the flexor carpi ulnaris. The 'indifferent' electrode ( $5 \mathrm{~mm}$ bared tip) was placed subcutaneously at a transverse distance of at least $4 \mathrm{~cm}$ from the stigmatic electrode. Sensory action potentials were recorded according to the procedure described by Buchthal and Rosenfalck (1966). In brief, the stimulus was a rectangular pulse $0.2 \mathrm{msec}$ in duration, applied via a double-screened transformer to surface electrodes on the little finger (digit V), the cathode proximal. The stimulus current was recorded on one channel of the oscilloscope. A current of not less than $60 \mathrm{~mA}$ was used, which is at least three times the current required to elicit a maximal response in normal subjects. Whenever possible, it was ascertained that the stimulus was in fact supramaximal by increasing the current to beyond the point at which the potential ceased to increase in amplitude. Single sweeps and the superposition of 20 sweeps were photographed; in addition, except when recording normal potentials at the wrist, an electronic averager was used on-line; 500 to 1,000 responses were averaged together with a calibration signal (Andersen and Buchthal, 1966). For control, the same number of sweeps was then averaged with the electrodes in position but without stimulus.

Conduction velocity in the fastest fibres $\left(v_{s}\right)$ was calculated for the segments digit $\mathrm{V}$ to wrist, wrist to below-sulcus, below- to above-sulcus and above-sulcus to axilla. The latency of the potential was measured from the onset of the stimulus to the peak of the first positive deflection. The distances were measured between the stimulating cathode and the stigmatic electrode at the wrist and between stigmatic electrodes at the four sites. 
TABLE IV

SENSORY AND MOTOR CONDUCTION IN THE ULNAR NERVE IN 36 NORMAL SUBJECTS AGED 18 TO 89 YEARS

\begin{tabular}{|c|c|c|c|c|c|c|c|}
\hline \multirow[t]{2}{*}{ Sensory } & \multirow[b]{3}{*}{$\begin{array}{l}\text { Wrist } \\
\text { Below-sulcus } \\
\text { Above-sulcus }\end{array}$} & \multicolumn{3}{|c|}{$\begin{array}{c}18-65 y r \\
21 \text { subjects }\end{array}$} & \multicolumn{3}{|c|}{$\begin{array}{c}70-89 y r \\
5\left(15^{1}\right) \text { subjects }\end{array}$} \\
\hline & & (Mean) & $(S D)$ & $(95 \%)$ & (Mean) & $(S D)$ & $(95 \%)$ \\
\hline Sensory action potential amplitude $(\mu \mathrm{V})$ & & $\begin{array}{c}14 \cdot 5 \\
6 \cdot 5 \\
5\end{array}$ & $\begin{array}{l}7 \\
2 \cdot 5 \\
2\end{array}$ & $\begin{array}{l}8 \cdot 5 \\
3 \\
2\end{array}$ & $\begin{array}{l}6 \\
3 \\
3\end{array}$ & $\begin{array}{l}3 \\
2 \\
1\end{array}$ & $\begin{array}{l}1.5 \\
0.5 \\
0.5\end{array}$ \\
\hline Total duration sensory action potential (msec) & $\begin{array}{l}\text { Wrist } \\
\text { Below-sulcus } \\
\text { Above-sulcus }\end{array}$ & $\begin{array}{l}2 \cdot 7 \\
6 \cdot 6 \\
9 \cdot 0\end{array}$ & $\begin{array}{l}0 \cdot 5 \\
1 \cdot 4 \\
2 \cdot 0\end{array}$ & $\begin{array}{r}3.7 \\
9.4 \\
13 \cdot 0\end{array}$ & & & \\
\hline Sensory conduction velocity $(\mathrm{m} / \mathrm{sec})$ & $\begin{array}{l}\text { Dig. V-wrist } \\
\text { Wrist-bel. sul. } \\
\text { Wrist-ab. sul. } \\
\text { Bel.-ab. sul. }\end{array}$ & $\begin{array}{l}55 \\
71 \\
66 \\
58\end{array}$ & $\begin{array}{l}4 \cdot 5 \\
4 \\
3 \\
4\end{array}$ & $\begin{array}{l}49 \\
63 \\
60 \\
50\end{array}$ & $\begin{array}{l}50 \\
64 \\
59 \\
54\end{array}$ & $\begin{array}{l}4 \\
2 \\
2 \\
5\end{array}$ & $\begin{array}{l}42 \\
60 \\
55 \\
44\end{array}$ \\
\hline
\end{tabular}

Motor

\begin{tabular}{|c|c|c|c|c|c|c|c|}
\hline Motor conduction velocity $(\mathrm{m} / \mathrm{sec})$ & $\begin{array}{l}\text { Ab. sul.-wrist } \\
\text { Bel. sul.-wrist } \\
\text { Ab. sul.-bel. s. }\end{array}$ & $\begin{array}{l}63 \\
69 \\
52\end{array}$ & $\begin{array}{l}3 \cdot 5 \\
5 \cdot 5 \\
4\end{array}$ & $\begin{array}{l}56 \\
60 \\
44\end{array}$ & $\begin{array}{l}56 \\
61 \\
50\end{array}$ & $\begin{array}{l}3 \\
5 \\
2\end{array}$ & $\begin{array}{l}50 \\
51 \\
46\end{array}$ \\
\hline Distal motor latency (msec) & $\begin{array}{l}\text { Wrist-hypoth. (corr. to } 7 \mathrm{~cm} \text { ) } \\
\text { - hypothenar (uncorrected) } \\
\text { - 1st dorsal interosseous }\end{array}$ & $\begin{array}{l}2.4 \\
2 \cdot 3 \\
3 \cdot 2^{1}\end{array}$ & $\begin{array}{l}0 \cdot 3 \\
0 \cdot 3 \\
0.3\end{array}$ & $\begin{array}{l}3 \cdot 0 \\
2 \cdot 9 \\
3 \cdot 8\end{array}$ & $\begin{array}{l}2 \cdot 7 \\
2 \cdot 8 \\
3 \cdot 4\end{array}$ & $\begin{array}{l}0 \cdot 3 \\
0 \cdot 3 \\
0 \cdot 3\end{array}$ & $\begin{array}{l}3 \cdot 3 \\
3 \cdot 4 \\
4 \cdot 0\end{array}$ \\
\hline Amplitude of evoked potential (mV) & $\begin{array}{l}\text { Wrist-hypothenar } \\
\text { Wrist-1st dors. int. }\end{array}$ & $\begin{array}{l}21 \\
26^{1}\end{array}$ & $\begin{array}{l}7 \\
8\end{array}$ & $\begin{array}{r}7 \\
10\end{array}$ & $\begin{array}{l}16 \\
17\end{array}$ & $\begin{array}{l}7 \\
10 \\
g e-30)\end{array}$ & $\begin{array}{l}2 \\
2\end{array}$ \\
\hline Distal motor latency (msec) & $\begin{array}{l}\text { Above-sulcus-flexor carpi ulnaris } \\
(9 \text { to } 15 \mathrm{~cm})\end{array}$ & \multicolumn{3}{|c|}{ (range $2 \cdot 5-3 \cdot 8)^{3 \cdot 1}$} & \multicolumn{3}{|c|}{ (range $3 \cdot 0-4 \cdot 1$ ) } \\
\hline Amplitude of evoked potential (mV) & Flexor carpi ulnaris & $18^{1}$ & 7 & 4 & 13 & 4 & 5 \\
\hline
\end{tabular}

'Subjects aged 40 to 65 only.

The sensory potential amplitudes are larger than those given by Buchthal and Rosenfalck (1966) because the recording electrode was placed by means of the motor threshold. The present conduction velocities are slightly faster and more uniform because of improved laboratory technique

The amplitude was measured peak-to-peak. The shape of the potential was evaluated according to its duration and degree of synchronization.

2. MOTOR The electrodes used for recording sensory potentials were then used to evoke a muscle action potential. The motor threshold $(<1 \mathrm{~mA})$ was checked to ensure that the needles were still close to the nerve. The stimulus, a rectangular current pulse $0.2 \mathrm{msec}$ in duration, was increased to at least 10 times the motor threshold and muscle action potentials were led off by concentric needle electrodes $0.45 \mathrm{~mm}$ in diameter with a leading-off area of $0.07 \mathrm{~mm}^{2}$ placed in a hypothenar muscle and in the first dorsal interosseous.

The distal latency was measured as the time interval between the onset of the stimulus and the onset of the initial deflection of the muscle action potential. Conduction velocity in the fastest fibres $\left(\mathrm{v}_{\mathrm{m}}\right)$ was calculated for the segments axilla to above-sulcus, above- to belowsulcus and below-sulcus to wrist. The amplitude was measured peak-to-peak and the degree of synchronization noted. When stimulating in the above-sulcus position, the same parameters were used for the flexor carpi ulnaris.

3. eLECTROMYOGRAPHY Thirty-six lesions were inves- tigated by electromyography of the hypothenar group of muscles or the first dorsal interosseous or both; the first dorsal interosseous was often so wasted that the exploring needles were probably in or very close to the adductor pollicis. Three concentric needle electrodes $0.45 \mathrm{~mm}$ in diameter with a leading-off area of $0.07 \mathrm{~mm}^{2}$ were connected to the three channels of an electromyograph (DISA type $14 \mathrm{~A} \mathrm{30}$ ), the differential amplifier of which had an input impedance of $200 \mathrm{M} \Omega$ shunted with $15 \mathrm{pF}$ (balanced), a lower frequency limit ( $3 \mathrm{db}$ down) of $2 \mathrm{c} / \mathrm{s}$ and an upper frequency limit ( $3 \mathrm{db}$ down) of $10,000 \mathrm{c} / \mathrm{s}$. The parameters studied were the incidence of fibrillation potentials and positive sharp waves, the pattern of activity during full voluntary effort, and the mean action potential duration and incidence of polyphasic potentials during weak effort; at least 20 different motor unit potentials were recorded in each muscle.

\section{RESULTS}

\section{NORMAL SUBJECTS}

The electrophysiological findings with respect to both sensory and motor conduction were similar in the young and middle-aged and were put together (Table IV). Deviations from normal were regarded 
as significant when $P \leqq 0.05$. Sensory potentials were studied as to amplitude, duration and shape, and, since comparison of the potentials recorded below- and above-sulcus was essential, the way in which the potentials could change between these two sites was examined. In subjects from 18 to 65 years old the potential recorded above sulcus was $35 \%$ smaller (maximum $50 \%$ ) and $30 \%$ longer (maximum $50 \%$ ) than that recorded below, and none contained a late phase exceeding $20 \%$ of the amplitude of the main component; in subjects over 70 only amplitude was useful, since the degree of desynchronization varied widely.

The conduction velocity across the sulcus was slower than in the forearm in both sensory and motor fibres $(P=0.001)$ and motor conduction was slower than sensory in the trans-sulcal segment $(P=0.001)$. The distal latency to the first dorsal interosseous might be up to $1.6 \mathrm{msec}$ longer than to hypothenar muscles and still within the $95 \%$ limit.

\section{PATIENTS}

SENSORY Wrist A sensory potential was recorded in 45 of 50 cases; 39 potentials were diminished in amplitude (Fig. 1), of which 29 were also desynchronized and prolonged. Of the six potentials with normal amplitude, one was slightly desynchronized; these were of special interest in that they did not preclude a more proximal lesion (Table V). In five cases no potential could be recorded at the wrist or at any other site. Potentials of $1 \mu \mathrm{V}$ or less were associated with a severe decrease in conduction velocity across the sulcus $(40 \mathrm{~m} / \mathrm{sec}$ or less). Slowing from digit $\mathrm{V}$ to wrist was present in $67 \%$ of cases, though the mean velocity was only $13 \%$ below normal (Fig. 2). Slowing in the distal segment was accompanied by slowing in the forearm and across the sulcus except in the patient with a polyneuropathy.

Below-sulcus A sensory potential was recorded in 41 cases; 38 potentials were smaller than normal (Fig. 1), of which 33 were desynchronized but only 23 prolonged, unlike the potentials at the wrist, which, if desynchronized, were prolonged. A potential of normal amplitude, duration and shape was recorded in three of the cases which had been normal at the wrist. Of four cases in which a potential was recorded at the wrist, in one the potential was below the noise level and in the others the investigation was discontinued for technical or other reasons. Slowing of conduction from wrist to belowsulcus was present in $83 \%$ (Fig. 2) and the mean was $20 \%$ below normal, a higher incidence and degree than in the distal segment.

Above-sulcus A sensory potential was recorded in 38 cases; 37 potentials were smaller than normal
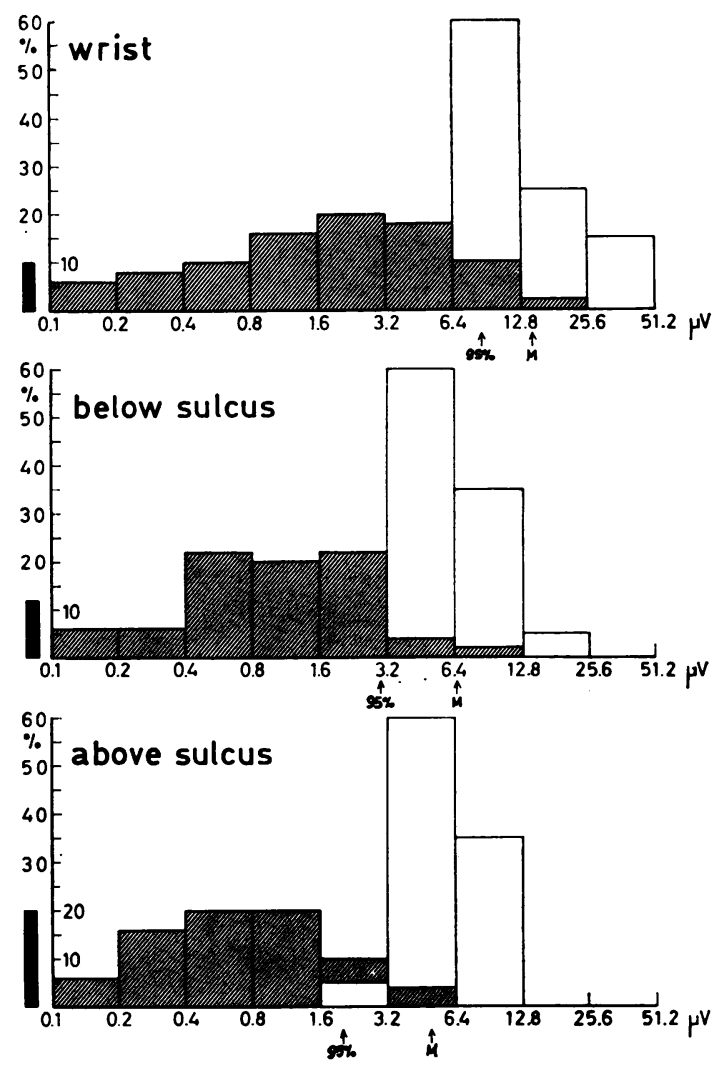

FIG. 1. Amplitude of sensory action potentials in 50 lesions of the ulnar nerve (hatched) and 20 normal nerves (open). The arrows denote the normal average $(M)$ and $95 \%$ lower limit. The black columns indicate the percentage of nerves in which the potential could not be obtained.

(Fig. 1), of which 35 were desynchronized but only 23 prolonged. A normal potential was found in one case. In four cases a potential was recorded belowbut not above-sulcus. Slowing of conduction across the sulcus was present in $86 \%$ of cases (Fig. 2), and was more pronounced than in either forearm or distal segment, the mean being $33 \%$ lower than normal.

MOTоR Wrist When stimulating the ulnar nerve at the wrist normal muscle action potentials were evoked in hand muscles in 35 cases; the amplitude was reduced in 12 , all but three of which were associated with severe slowing of conduction across the sulcus $(30 \mathrm{~m} / \mathrm{sec}$ or less), and in three the potentials were absent. A quarter of the potentials was abnormally split up, but this was not necessarily associated with low amplitude or prolonged latency. The distal motor latency was prolonged in 
TABLE V

CHANGES IN THE SENSORY POTENTIAL AT THE ELBOW WITH A NORMAL POTENTIAL AMPLITUDE AT THE WRIST

\begin{tabular}{|c|c|c|c|c|c|c|c|}
\hline \multirow[t]{2}{*}{ Case no. } & \multirow{2}{*}{$\begin{array}{l}\text { Wrist } \\
(\mu \mathrm{V})\end{array}$} & \multirow{2}{*}{\multicolumn{2}{|c|}{$\begin{array}{l}\text { Below-sulcus } \\
(\mu \mathrm{V}) \quad \text { (shape) }\end{array}$}} & \multirow{2}{*}{\multicolumn{2}{|c|}{$\begin{array}{l}\text { Above-sulcus } \\
(\mu \mathrm{V}) \quad \text { (shape) }\end{array}$}} & \multicolumn{2}{|c|}{$v_{S}(\mathrm{~m} / \mathrm{sec})$} \\
\hline & & & & & & $w-b$ & $b-a$ \\
\hline 16 & $9 \cdot 6$ & $2 \cdot 2$ & D & $3 \cdot 0$ & D & 64 & 33 \\
\hline 10 & $10 \cdot 0$ & 2.0 & $\mathbf{N}$ & & sent & 57 & - \\
\hline 44 & $10 \cdot 0$ & $4 \cdot 2$ & $\mathbf{N}$ & $2 \cdot 4$ & $\mathbf{N}$ & 65 & 41 \\
\hline 57 & $10 \cdot 0$ & $2 \cdot 4$ & D & $2 \cdot 8$ & D & 69 & 59 \\
\hline 38 & 12.0 & $3 \cdot 2$ & $\mathbf{N}$ & $4 \cdot 4$ & D & 62 & 39 \\
\hline 27 & $14 \cdot 2$ & $7 \cdot 6$ & $\mathbf{N}$ & $4 \cdot 2$ & D & 64 & 52 \\
\hline Normal & $14 \cdot 5$ & 6.5 & & $5 \cdot 0$ & & 71 & 58 \\
\hline $\begin{array}{l}\text { Lower } \\
\text { limit }^{1}\end{array}$ & $8 \cdot 5$ & 3.0 & & $2 \cdot 0$ & & 63 & 50 \\
\hline
\end{tabular}

$\mathrm{D}=$ abnormally desynchronized; $\mathrm{N}=$ normal; $\mathrm{v}_{\mathrm{g}}=$ conduction velocity in fastest fibres; $w=$ wrist; $b=$ below-sulcus; $a=$ abovesulcus.

${ }^{2}$ Derived from standard deviation or cumulative distribution curve.

\section{TABLE VI}

MOTOR CONDUCTION IN THE ULNAR NERVE OF A 74-YEAR-OLD PATIENT WITH OSTEOARTHRITIS AND DEFORMITY OF THE ELBOW WHO USED ELBOW CRUTCHES

\begin{tabular}{lcc}
\hline & $\begin{array}{c}\text { Hypothenar } \\
\text { muscles }\end{array}$ & $\begin{array}{c}\text { 1st dorsal } \\
\text { interosseous }\end{array}$ \\
\hline Distal motor lat. (msec) & $3 \cdot 6$ & $6 \cdot 0$ \\
Amplit. of evoked pot. $(\mathrm{mV})$ & 24 & $3 \cdot 5$ \\
$\mathrm{v}_{\mathrm{m}}$ below-sulcus to wrist $(\mathrm{m} / \mathrm{sec})$ & 33 & 27 \\
$\mathrm{v}_{\mathrm{m}}$ above-below sulcus $(\mathrm{m} / \mathrm{sec})$ & 33 & 19 \\
\hline
\end{tabular}

$40 \%$ (Fig. 3), all of which showed slowing in the forearm except one-a patient with a severe lesion of unknown cause had slightly prolonged distal latencies, normal conduction velocity in the forearm, and severe slowing across the sulcus. The normal difference between latencies to the hypothenar group of muscles and the first dorsal interosseous was exceeded in only one patient, an elderly lady with osteoarthritis and limitation of extension at the elbow who used elbow crutches and supported much of her weight on her palms (Table VI). Damage mainly to fibres supplying the first dorsal interosseous by a lesion at the sulcus seemed the most likely explanation, though an additional local pressure lesion in the palm could not be excluded.

Below-sulcus As in normal subjects, the potentials evoked when stimulating below-sulcus were usually the same as or not less than half the amplitude of those evoked by stimulating at the wrist: in four cases, however, they were smaller. The conduction velocity in the forearm in fibres supplying hypothenar muscles or the first dorsal interosseous or both was slowed in $75 \%$ of cases (Fig. 3), the mean being $23 \%$ below normal.

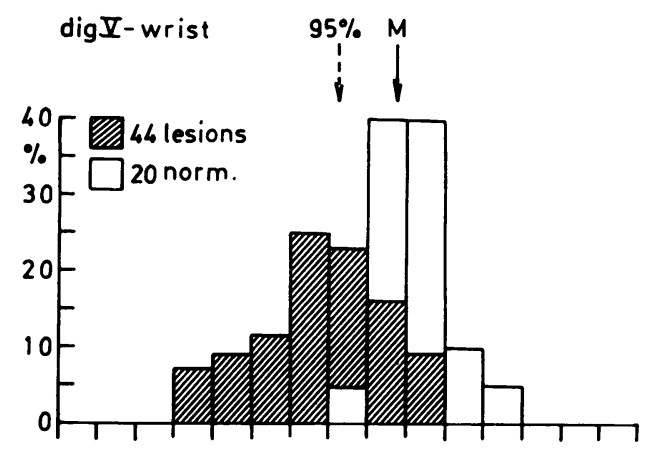

wrist-bel.sulc.
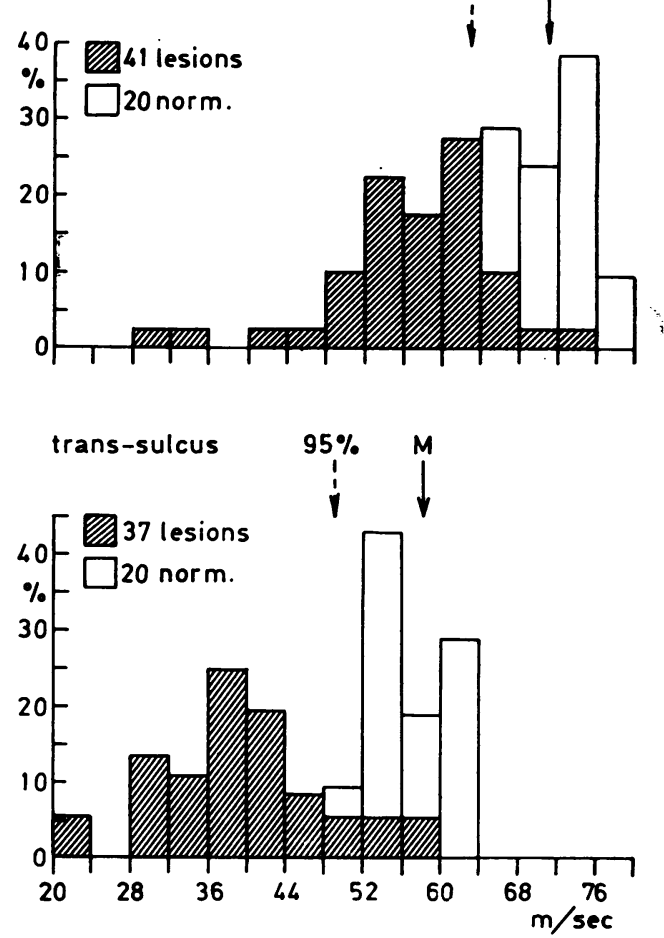

FIG. 2. Sensory conduction velocity in three segments of the ulnar nerve. The arrows denote the normal average $(M)$ and $95 \%$ lower limit.

Above-sulcus In one case the amplitude of potentials evoked in the hand muscles was smaller than when stimulating below-sulcus (above: $50 \mu \mathrm{V}$ and $160 \mu \mathrm{V}$; below: $3.5 \mathrm{mV}$ and $8 \mathrm{mV}$ ), but this comparison was not otherwise of value in localization. The conduction velocity across the sulcus was slowed in $85 \%$ (Fig. 3), the mean being $29 \%$ below normal; if only one hand muscle had been used the yield would have fallen to $75 \%$. A potential 
could be evoked in the flexor carpi ulnaris even when fibres to hand muscles were blocked; it was reduced in amplitude in six cases, desynchronized in five and delayed in 21 (Fig. 3). The latency to this muscle was slightly prolonged in three cases in which the trans-sulcal conduction velocity was normal.

THE 'ABOVE-SULCUS' TO 'AXILLA' SEGMENT In none of 10 cases did the 'axilla' differ from the abovesulcus position with respect to sensory potentials or evoked muscle action potentials. Conduction velocities were not studied in this segment in normal subjects, but assuming them to be at least as fast as in the forearm, sensory conduction was slowed in five and motor in three cases. In four cases (15 R, $16,17,20$, Table VII) the inclusion of the segment proximal to the elbow would have made localization possible if motor conduction alone had been studied, but in the others it was merely confirmatory.

LOCALIZATION TO THE elbow (Table VIII) The elbow was indicated as the site of damage by the sensory investigation in 34 cases, of which transsulcal slowing occurred in 30 and a change in the sensory action potential across the sulcus in four, and by the motor investigation in 35 , of which trans-sulcal slowing occurred in 25 and an increased latency to flexor carpi ulnaris in a further 10 .
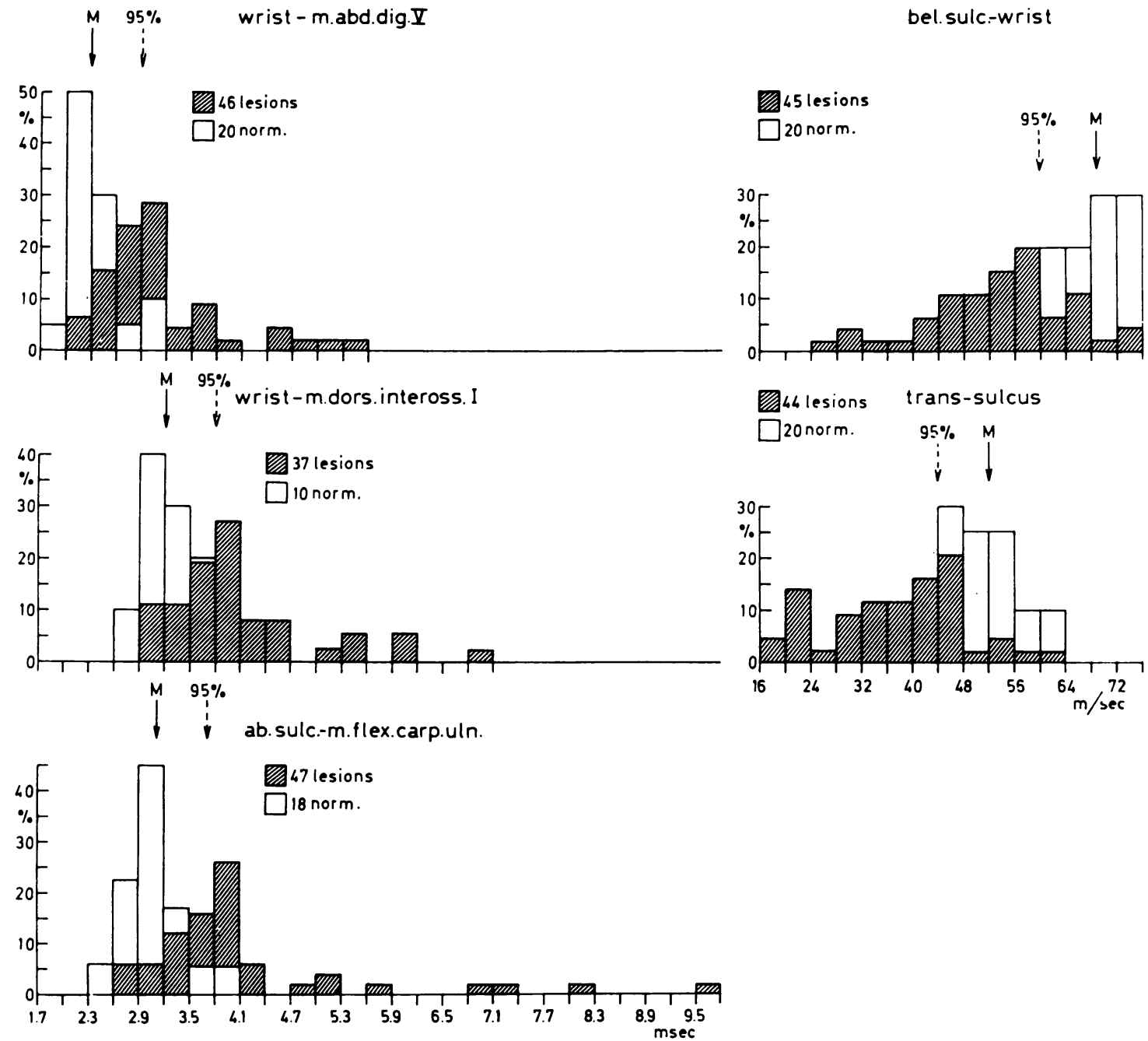

FIG. 3. Distal motor latency (left) and motor conduction velocity (right) in lesions of the ulnar nerve and in normal nerves. The arrows denote the normal average $(M)$ and $95 \%$ lower limit. 
In 23 cases the lesion could have been localized by either sensory or motor parameters. In two cases the electrophysiological investigation failed to indicate the site of the lesion.

ELECTROMYOGRAPHY (Table IX) Fibrillation potentials and positive sharp waves in more than two sites

\section{TABLE VII}

SENSORY $\left(v_{s}\right)$ AND MOTOR CONDUCTION VELOCITY $\left(v_{m}\right)$ IN THREE ADJACENT SEGMENTS OF THE ULNAR NERVE IN 10 CASES

\begin{tabular}{ccccccc}
\hline $\begin{array}{c}\text { Case } \\
\text { no. }\end{array}$ & $w-b$ & $\begin{array}{c}v_{s} \\
b-a\end{array}$ & $a-a x$ & $w-b$ & $\begin{array}{c}v_{m} \\
b-a\end{array}$ & $a-a x$ \\
\hline 9 & 52 & 36 & 55 & 59 & 35 & 56 \\
13 & 52 & 34 & 54 & 61 & 38 & 64 \\
$15 R$ & - & 40 & - & 25 & 20 & 63 \\
$15 L$ & 60 & 29 & 75 & 58 & 29 & 50 \\
16 & 64 & 33 & 65 & 55 & 43 & 73 \\
17 & 61 & 29 & 50 & 34 & 28 & 63 \\
18 & 62 & 28 & 64 & 68 & 34 & 64 \\
19 & 57 & 47 & 53 & 58 & 39 & 73 \\
20 & 60 & 42 & 49 & 51 & 44 & 70 \\
25 & 46 & 33 & 66 & 51 & 22 & 52 \\
\hline
\end{tabular}

$\mathrm{w}=$ wrist $; \mathrm{b}=$ below-sulcus; $\mathrm{a}=$ above-sulcus; $\mathbf{a x}=$ ' $\mathrm{axilla}$ '.

TABLE VIII

PARAMETERS BY WHICH 48 LESIONS OF THE ULNAR NERVE COULD BE LOCALIZED TO THE REGION OF THE CUBITAL SULCUS

\begin{tabular}{lr}
\hline $\begin{array}{l}\text { Sensory } \\
\text { Trans-sulcal slowing }\end{array}$ & 30 \\
Increased duration of potential above sulcus & 8 \\
$\begin{array}{l}\text { Reduction in amplitude or disappearance of potential above } \\
\quad \text { sulcus }\end{array}$ & 7 \\
$\begin{array}{l}\text { Increased desynchronization of potential above sulcus } \\
\text { Shortened duration of potential above sulcus }\end{array}$ & 5 \\
\hline $\begin{array}{l}\text { Motor } \\
\text { Trans-sulcal slowing }\end{array}$ & 26 \\
$\quad$ Flexor carpi ulnaris & \\
$\quad$ increased distal mot. lat. & 21 \\
$\quad$ decreased amplitude & 6 \\
\hline
\end{tabular}

TABLE IX

THE RESULTS OF ELECTROMYOGRAPHY

\begin{tabular}{lcc}
\hline & $\begin{array}{c}\text { Hypothenar } \\
\text { muscles } \\
\text { Lesions examined (no.) }\end{array}$ & 1st D.I./Add. poll \\
\hline $\begin{array}{c}\text { Pattern at full voluntary effort } \\
\text { interference or mixed to } \\
\text { interference }\end{array}$ & 19 & 23 \\
$\quad \begin{array}{l}\text { discrete activity } \\
\text { no activity }\end{array}$ & 13 & 16 \\
$\begin{array}{l}\text { Fibrillation and /or positive sharp } \\
\text { waves }\end{array}$ & 3 & 5 \\
$\begin{array}{l}\text { Action potential duration } \\
\text { prolonged }>20 \%\end{array}$ & 20 & 2 \\
$\begin{array}{l}\text { Polyphasia }>12 \% \\
\text { Ply }\end{array}$ & 8 & 13 \\
\hline
\end{tabular}

in the muscle outside the endplate zone were $Z$ recorded as often in the hypothenar muscles as in $\stackrel{\oplus}{=}$ the first dorsal interosseous, consistent with the absence of lesions in the hand. Evidence of de- $\subseteq$ nervation was associated with abnormalities of motor or sensory evoked potentials or conduction.

RELATION TO CLINICAL FINDINGS Aetiology When the lesions were severe, mechanical derangement of $\vec{z}$ the elbow and compression during general anaesthesia were relatively the most common causes. Thus, $\stackrel{\vec{S}}{+}$ sensory potentials of $1 \mu \mathrm{V}$ or less at the wrist, trans-sulcal sensory conduction velocities of 40 을 $\mathrm{m} / \mathrm{sec}$ or less and trans-sulcal motor velocities of $\frac{\bar{\rho}}{\square}$ $30 \mathrm{~m} / \mathrm{sec}$ or less were twice as frequent in these $\mathscr{\Phi}$

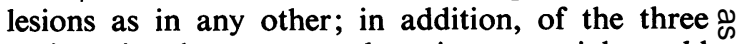
patients in whom no muscle action potentials could $\rightarrow$ be evoked when stimulating at the wrist two followed anaesthesia and the third had a marked deformity of $\vec{\omega}$ the elbow joint.

Pure sensory lesions of seven patients who on clinical grounds had pure sensory lesions, six proved to have damage to motor fibres also. Thus, motor $N$ conduction velocity across the sulcus was slowed in five (34 to $42 \mathrm{~m} / \mathrm{sec}$ ), one of whom also had sligh slowing in the forearm $(53 \mathrm{~m} / \mathrm{sec})$, and the latene to flexor carpi ulnaris was prolonged in one $(40)$ msec).

Pure motor lesions In the three patients who of clinical grounds had pure motor lesions senso potentials were small and desynchronized at $\vec{\oplus}$ levels, and sensory conduction velocity was slowe across the sulcus ( 29 to $47 \mathrm{~m} / \mathrm{sec}$ ) and in the forearm (55 to $60 \mathrm{~m} / \mathrm{sec}$ ).

No physical signs (Table 10) (a) With symptoms (one patient) A patient whose ulnar nerve had been transposed for a lesion apparently resulting $\mathbb{\Phi}$ from a sudden violent extension at the elbow began to notice paraesthesiae in the contralateral little $\stackrel{\vec{O}}{3}$

TABLE $X$

RESULTS OF THE SENSORY INVESTIGATION IN PATIENTS WITHOUT PHYSICAL SIGNS

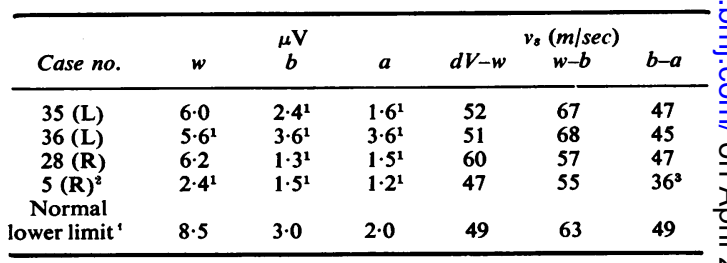

$v_{\mathbf{s}}=$ conduction velocity in fastest fibres; $d V=$ digit $V ; w=$ wrist $;$ $\mathrm{b}=$ below-sulcus; $\mathrm{a}=$ above-sulcus; $(\mathrm{L})=$ left $;(R)=$ right.

${ }^{1}$ Desynchronized and prolonged.

${ }^{2}$ Patient with paraesthesiae in digit V.

${ }^{3}$ Trans-sulcal motor conduction velocity also $36 \mathrm{~m} / \mathrm{sec}$.

- Derived from standard deviation or cumulative distribution curve. 


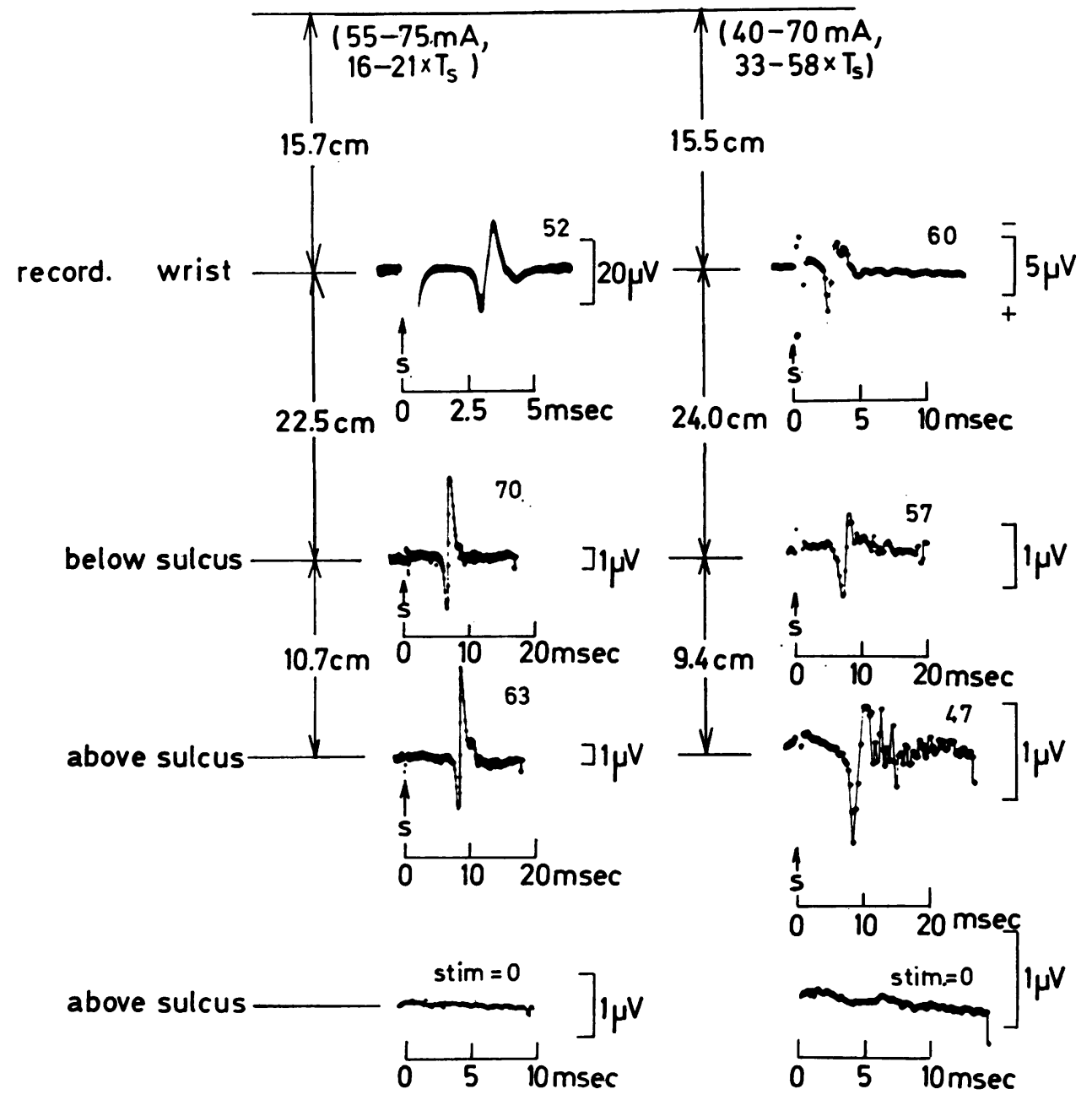

FIG. 4. Sensory action potentials in a normal subject aged 54 years (left) and on the clinically normal side in a patient (right) with a lesion of the contralateral ulnar nerve at the elbow (case 28R, 34 years old, Table X). The potentials, evoked by supramaximal stimuli to digit $V(40$ to $75 \mathrm{~mA})$, were recorded at the wrist by photographic superposition or electronic averaging, at other sites by electronic averaging. The trace below shows averaging with the electrodes in place but with stimulus zero. The figure above each trace indicates the conduction velocity in $\mathrm{m} / \mathrm{sec}, \mathrm{S}$ the stimulus and $T_{8}$ the sensory threshold. The temperature near the nerve was 34 to $36^{\circ} \mathrm{C}$.

finger; partial or complete dislocation of the nerve occurred on flexion at the elbow. The electrophysiological investigation (case $5 \mathrm{R}$ ) showed small, desynchronized sensory potentials and trans-sulcal slowing of both sensory and motor conduction.

(b) Without symptoms (three patients) Sensory potentials tended to be somewhat reduced in amplitude and markedly desynchronized. In two cases $(35 \mathrm{~L}, 36 \mathrm{~L})$ the degree of trans-sulcal sensory slowing indicated the site of the lesion, and in the third ( $28 \mathrm{R})$ the potential recorded above sulcus was much more desynchronized than that below (Fig. 4). Motor conduction was normal.

Sensory threshold When the amplitude of the sensory potential recorded at the wrist was $0.5 \mu \mathrm{V}$ or less the threshold to electrical stimulation of digit $\mathrm{V}$ was raised; when the amplitude of the potential was greater the threshold might be increased or normal, but a normal amplitude was associated with a normal threshold. 
Two point discrimination Impairment of two point discrimination was in 11 of 14 instances associated with a sensory potential at the wrist of less than $1 \mu \mathrm{V}$, but such small potentials were more often found when the test was normal.

\section{DISCUSSION}

AETIOLOGY The proportion of patients with ulnar nerve lesions of unknown cause has been reported as 12 to $17 \%$ (Gay and Love, 1947; McGowan, 1950; Mumenthaler, 1960; Kaeser, 1963). The incidence of $38 \%$ in our series may reflect a pattern of referral (neurophysiological investigation being considered unnecessary in obvious cases), but is also a matter of classification: the authors quoted have regarded spontaneous dislocation of the ulnar nerve at the elbow as a cause in itself. Childress (1956) found that $16 \%$ of normal ulnar nerves dislocate on elbow flexion, $12 \%$ as far as the tip of the medial epicondyle ('partial dislocation') and $4 \%$ completely. The incidence in our patients was $20 \%$, and in the 'unknown' group 26\%; this may indicate that dislocation per se was the cause of the lesions, but if so it is remarkable that lesions of the ulnar nerve are not more common in the general population, and it seems more likely that a nerve which leaves its bed is simply more vulnerable. Of five patients whose nerves dislocated, four gave histories of the onset of symptoms after episodes of compression or acute trauma and one had a gross deformity of the elbow.

LESIONS AFTER GENERAL ANAESTHESIA Seven patients first noticed symptoms upon regaining consciousness after general anaesthesia; after a second operation a week later one patient promptly developed symptoms in the contralateral hand; on both occasions symptoms had appeared on the side used for transfusion. Jones (1967) described a 50-year-old patient who complained of cramp in the hand five minutes after recovering from anaesthesia; a severe ulnar lesion developed in the course of a few days, but mild diabetes was then discovered. No such predisposing factor was found in any of our patients. Of 30,000 patients given anaesthesia in Stockholm from 1940-45 eight developed lesions of the ulnar nerve (Dhunér, 1950). Mumenthaler (1960) held that such lesions were due to lying in bed and were not related to narcosis, but this could not have been the case in our patients because of the immediate post-operative onset; moreover, the lesions in the post-operative group were far more severe than in the patients in whom bed rest seemed to be responsible. Wylie and Churchill-Davidson (1966) warn that the ulnar nerve 'may be compressed between the bone and the edge of the operating table should the arm not be placed close to the side of the body in the horizontal position'.

ASYMPTOMATIC LESIONS Tingling and even loss of feeling is common in the region supplied by the ulnar $D_{0}$ nerve; it may awaken one at night and often occurs when resting the bent elbow upon a hard surface, $\frac{O}{\overline{0}}$ but is normally transient and not regarded as indicating a lesion of the nerve. Gilliatt and Thomas : (1960) found no abnormalities of conduction in the ulnar nerve in patients with paraesthesiae and no physical signs, but Kaeser (1963) was unable to record a sensory potential from the clinically normal $\frac{\bar{\omega}}{2}$ nerve in two of eight patients. In our three patients sensory potentials were reduced in amplitude and were prolonged to a degree suggesting that immature, regenerating fibres were responsible for the latest phases (Fig. 4). It may therefore be supposed that damage and repair were competing in the region of the sulcus without loss of fibres and consequent impairment of function, but what predisposed these patients to develop bilateral lesions is not known; no anatomical factor was evident, there was no reason to $\omega$ suspect sub-clinical polyneuropathy and no familit i history of increased susceptibility to compressive $\infty$ nerve lesions (Earl, Fullerton, Wakefield, an $\$$ 은 Schutta, 1964). That these asymptomatic lesions di $\vec{\phi}$ not represent merely part of a spectrum of damage to be found in the population at large is indicated bo the homogeneous findings in randomly selected normal subjects.

DIFFERENTIAL DIAGNOSIS A lesion of the ulnar nerve had been diagnosed or was suspected by the referring physician in all but five patients, of whom four had radiological changes in the cervical spine and one a polyneuropathy. Of the four with a possible cervical root lesion three had hypaesthesia which included both sides of the ring finger, two had pain radiating from the neck down the arm, and one, in whom the triceps reflex was absent, complained of a vague pain in the left scapular region. In each case electrophysiological investigation showed transsulcal slowing of conduction in sensory and motor fibres. The patient with polyneuropathy had suffered from a progressive paraparesis for many months and an earlier electromyographic investigation had shown a severe, bilateral, peripheral neurogenic affection of the legs with normal distal sensory and motor conduction in a median nerve. Only six weeks later slight wasting of the interossei was noticed, and investigation of the ulnar nerve showed small, desynchronized sensory potentials, shorter above than below the sulcus; pressure upon the nerve when lying in bed had presumably precipitated 
the first manifestation of neuropathy in the upper extremity.

ELECTROPHYSIOLOGICAL FINDINGS IN NORMAL SUBJECTS The duration of a sensory action potential depends upon the conduction velocity of the slowest fibres contributing to it and the possibility of discriminating the late components from noise. The introduction of electronic averaging has turned this formerly theoretical consideration into a matter of some practical importance, since if temporal dispersion can be shown to have increased disproportionately over a given distance a lesion may be suspected on this ground alone. In subjects over 70 years such comparisons were of little value as potentials tended to be markedly, and fairly equally, desynchronized at all levels; this was sufficient to explain the smaller amplitude of the potentials found at this age and was consistent with Vizoso's (1950) observation that ulnar nerve fibres at the wrist showed a greater scatter of internode lengths for a given fibre diameter in an 80-year-old man than in an 18-year-old girl and even than in a 67-year-old woman, suggesting local demyelination and remyelination or regeneration after degeneration.

A slower conduction velocity across the sulcus than in the forearm in healthy subjects has been accepted as normal by some workers (Carpendale, 1966; Tascon-Alonzo, 1963 - quoted by Carpendale), but Schubert (1964) found that the anomaly disappeared when the distance between electrodes was measured with the forearm in pronation instead of supination. Presumably the descent of the nerve from its superficial situation in the cubital sulcus to a course deep to the flexor carpi ulnaris makes the length of the trans-sulcal segment measured on the skin slightly less than the true length, while pronation results in a more accurate measurement. Kaeser (1963) found no local slowing in normal subjects when he measured with the elbow at a right angle. We continued to examine patients with the elbow extended and the forearm supinated because of the greater convenience in placing needle electrodes.

SENSORY THRESHOLD Despite the difficulties inherent in measuring the sensory threshold it varied little in normal subjects and the routine performance of this test at least confirmed that most sensory fibres could be blocked before a rise in threshold occurred (Buchthal and Rosenfalck, 1966). It has been suggested that when pin prick evokes a sensation of increased intensity and unpleasantly altered quality the pain threshold is lowered (Lanier, Carney, and Wilson, 1935), but four patients with this sign had some of the highest thresholds found.
PURE SENSORY LESIONS That only sensory fibres showed electrophysiological abnormalities in one patient with signs and symptoms and three with neither, and that motor fibres were not affected alone suggests that sensory fibres are the first to be damaged in lesions of the ulnar nerve at the elbow. Kaeser (1963) found motor slowing, confined to the trans-sulcal segment, in seven of nine patients without wasting or weakness; we found this in four of seven, but in a further patient there was also slowing in the forearm.

LOCALIZATION TO THE ELBOW An isolated lesion of the ulnar nerve is likely to lie in the elbow region when forearm muscles are affected, when there is gross deformity of the joint, or when there is a clear history of symptoms after trauma to the area. One or more of these criteria were present in $\mathbf{1 3}$ of the lesions described; electrophysiological investigation confirmed the localization in 12 and revealed it in a further 36. There remained one lesion which could not be localized on clinical or electrophysiological grounds.

The commonest electrophysiological indication of a lesion in the elbow region was a slowing of sensory or motor conduction or both across the sulcus, but to have localizing value the trans-sulcal velocity had to be not merely slower than normal but disproportionately slower than in the forearm; hence the lower number of lesions localized than expected from the incidence of slowing across the sulcus. Thus, Kaeser (1963) was able to localize $86 \%$ of lesions in the elbow region by means of trans-sulcal motor slowing; we found the same incidence of motor slowing in this segment, but could localize the lesion in only $50 \%$ because we found slowing in the forearm to be more common and more severe than Kaeser did. Although no deep palmar lesion was discovered, an unexpected benefit accrued from evoking potentials in both first dorsal interosseous and hypothenar muscles in that trans-sulcal slowing was sometimes evident in fibres to one but not the other; in our patients as a whole, however, fibres to the two groups were found to be equally affected, and we were unable to substantiate Osborne's (1959) clinical impression that gradual compression of the nerve in the cubital tunnel causes the interossei to waste more than the hypothenar muscles.

In the absence of local slowing in either sensory or motor fibres, four lesions could be localized only by changes in the shape of the sensory potential from below to above sulcus; however, a lesion at the elbow may result in the potential recorded above it being disproportionately longer than that recorded below, of the same duration or even shorter (Fig. 5), since late components may disappear when the fibres 


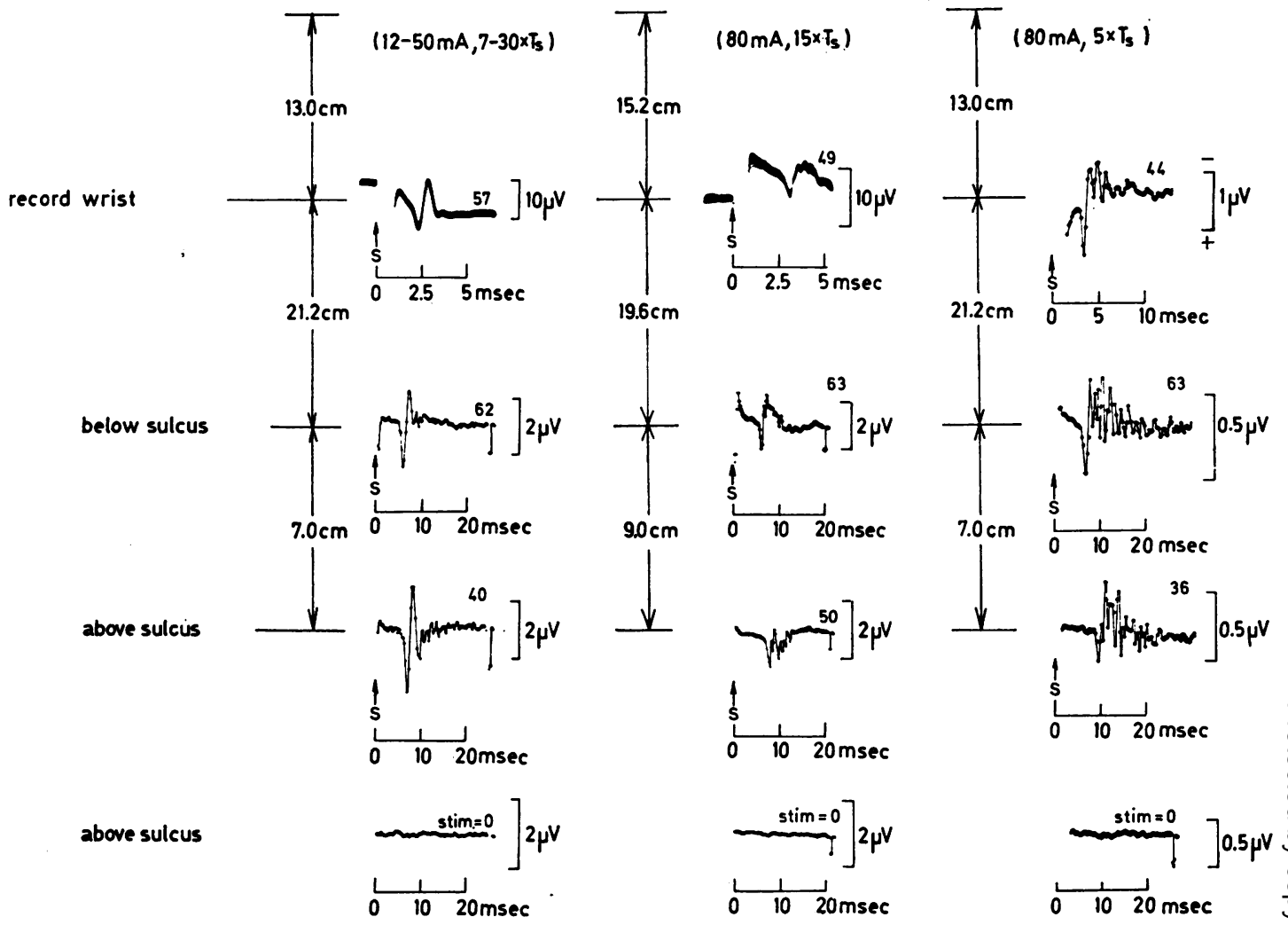

FIG. 5. Sensory action potentials in patients with early (left and centre) and advanced (right) lesions of the ulnar nerves at the elbow showing that the desynchronized potential recorded above-sulcus may be prolonged (left), within the normal. range of duration (centre) or shorter than the potential recorded below-sulcus (right). The procedure was as described in the legend to Figure 4.

responsible decrease in number or cease to conduct.

THE NERVE PROXIMAL TO THE LESION A lesion of the ulnar nerve in the upper arm is likely to involve the median nerve as well unless caused by a selective injury such as a bullet wound, but, although we found no lesion there, it proved necessary to study conduction velocity in the upper arm if motor fibres only were to be investigated.

In a study of experimental demyelination, Mayer and Denny-Brown (1964) found that conduction velocity in the sciatic nerve of the cat was normal proximal and distal to a lesion caused by tourniquet compression except when there was Wallerian degeneration. Lesions of the human ulnar nerve at the elbow are likely to comprise both types of pathological reaction, since Wallerian degeneration alone would not account for severe trans-sulcal slowing and demyelination alone would not explain slowing proximal to the elbow or, indeed, in the forearm. Moreover, both degeneration and de- myelination were found at the site of the naturally occurring chronic pressure lesion of median and ulnar nerves in the guinea-pig (Fullerton and Gilliatt, 1967), and slowing proximal to the lesion was associated with a reduction in fibre diameter and fibre density and thought to be due to retrograde changes in compressed fibres.

FLEXOR CARPI ULNARIS The distal latency to the flexor carpi ulnaris when stimulating the ulnar nerve above the sulcus was of greater value than might be expected from the infrequent clinical involvement of this muscle. Feindel and Stratford (1958) have suggested that the nerve branches to flexor carpi ulnaris, being smaller and lying more freely in the cubital tunnel, are less subject to compression than the large bulk of the main nerve, the vulnerability of which is frequently enhanced at this point by its being composed of one major funiculus, a variable number of fine satellite bundles and a relatively small amount of epineurial tissue (Sunderland, 1965). 
Perhaps for this reason it was possible to evoke a potential in the flexor when fibres supplying hand muscles had ceased to conduct.

THE SCHEME OF THE INVESTIGATION The relative value of different parts of the investigation in localizing the lesions is shown in Figure 6. Sensory and motor findings made an equal contribution, considered separately, but by combining different parts the yield was raised. The results in 10 cases in which the segment proximal to the elbow was included suggest that the value of studying motor conduction alone may be improved by making this a routine part of the procedure. However, the trend is towards earlier referral, often of patients with minimal complaints, and the results of the motor conduction study will in a certain proportion be borderline or negative and need to be supplemented by the more time-consuming sensory study or electromyography or both. Thus, fibrillation potentials in the flexor carpi ulnaris would indicate a lesion at or proximal to the elbow, and, if present in the first dorsal-interosseous-adductor pollicis group but not hypothenar muscles, would suggest a deep palmar lesion.

\section{SUMMARY}

Forty-six patients with lesions of one or both ulnar nerves were studied clinically and electrophysiologically and the findings compared with those in 36

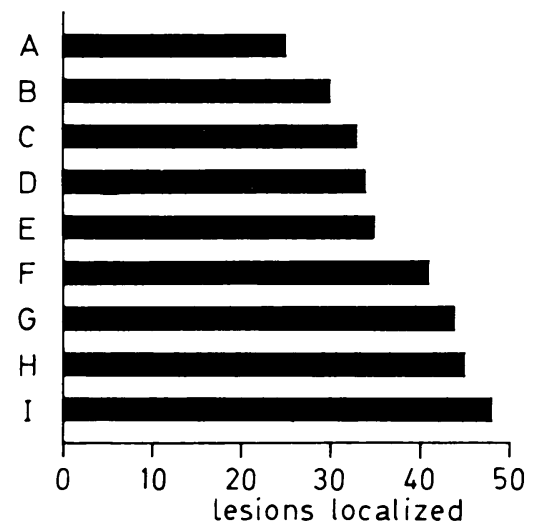

FIG. 6. Different schemes of investigation in localizing a lesion to the elbow in 50 ulnar nerves (recording or stimulating at wrist, below- and above-sulcus). $A=$ motor conduction velocity $(\mathrm{cv}) ; B=$ sensory $c v ; C=$ sensory and motor $c v ; D=$ sensory $c v+$ trans-sulcal changes in sensory action potential; $E=$ motor $c v-$ increased latency to flexor carpi ulnaris (f.c.u.); $F=$ sensory $c v-$ increased latency to f.c.u.; $G=$ sensory and motor $c v+$ increased latency to f.c.u.; $H=$ sensory $c v$ and potential changes - increased latency to f.c.u.; I = sensory and motor $c v$ isensory potential changes increased latency to f.c.u. normal subjects. Sensory and motor conduction velocity were measured in the elbow region, in the forearm, distal to the wrist and, in 10 cases, in the upper arm. In addition, the amplitude and shape of evoked sensory and muscle action potentials were compared at the different sites. The findings in normal subjects 18 to 65 years old did not differ, but sensory potentials were markedly desynchronized in those over 70 .

Three-quarters of the lesions were due to unknown causes, to compression during general anaesthesia or to trauma; the 'unknown' group included several with spontaneous dislocation of the nerve, considered to be a predisposing rather than a determining cause. Sensory fibres were the first to be affected in lesions of the ulnar nerve at the elbow. The patients most severely affected were those whose lesions followed general anaesthesia or were secondary to long-standing deformity of the elbow, but even when motor fibres supplying the intrinsic muscles of the hand were blocked a potential could be evoked in flexor carpi ulnaris.

Thirteen lesions could be localized on clinical grounds to the elbow region and none to the hand or wrist. Forty-eight of the 50 lesions could be localized by electrophysiological means; in one patient there was no indication as to the site of the lesion. The site was indicated by a disproportionate slowing of sensory or motor conduction at the elbow, a prolonged latency to the flexor carpi ulnaris or a change in the amplitude, duration or shape of the sensory potential from below to above the elbow. The yield of the different electrophysiological procedures singly and in combination has been described.

I wish to thank Professor Fritz Buchthal for his guidance, encouragement and criticism, and Dr. W. Trojaborg for his ready help. The work was supported by grants from the Danish State Research Foundation and the Danish National Association for Infantile Paralysis.

\section{REFERENCES}

Andersen, V. O., and Buchthal, F. (1966). Annual Report, Institute of Neurophysiology: University of Copenhagen.

Buchthal, F., and Rosenfalck, A. (1966). Evoked action potentials and conduction velocity in human sensory nerves. Brain Res., 3, $1-120$.

Carpendale, M. T. (1966). The localization of ulnar nerve compression in the hand and arm: an improved method of electroneuromyography. Arch. phys. Med., 47, 325-330.

Childress, H. M. (1956). Recurrent ulnar-nerve dislocation at the elbow. J. Bone Jt Surg., 38-A, 978-984.

Dhunér, K.-G. (1950). iverve injuries following operations: a survey of cases occurring during a six-year period. Anesthesiology, 11, 289-293.

Earl, C. J., Fullerton, P. M, Wakefield, G. S., and Schutta, H. S (1964). Hereditary neuropathy, with liability to pressure palsies. A clinical and electrophysiological study of four families. Quart. J. Med., 33, 481-498.

Feindel, W., and Stratford, J. (1958). The role of the cubital tunnel in tardy ulnat palsy. Canad. J. Surg., 1, 287-300. 
Fullerton, P. M., and Gilliatt, R. W. (1967). Median and ulnar neuropathy in the guinea-pig. J. Neurol. Neurosurg. Psychiat., 30, 393-402.

Gay, J. R., and Love, J. G. (1947). Diagnosis and treatment of tardy paralysis of the ulnar nerve. Based on a study of 100 cases. J. Bone Jt Surg., 29, 1087-1097.

Gilliatt, R. W., and Thomas, P. K. (1960). Changes in nerve conduction with ulnar lesions at the elbow. J. Neurol. Neurosurg. Psychiat., 23, 312-320.

Jones, H. D. (1967). Ulnar nerve damage following general anaesthetic. A case possibly related to diabetes mellitus. Anaesthesia, 22, 471-475.

Kaeser, H. E. (1963). Erregungsleitungsstörungen bei Ulnarisparesen. Dtsch. Z. Nervenheilk., 185, 231-243.

Lanier, L. H. Carney, H. M., and Wilson, W. D. (1935). Cutaneous innervation: an experimental study. Arch. Neurol. Psychiat. (Chic.), 34, 1-60.

McGowan, A. J. (1950). The results of transposition of the ulnar nerve for traumatic ulnar neuritis. J. Bone Jt Surg., 32-B, 293-301.
Mayer, R. F., and Denny-Brown, D. (1964). Conduction velocity in peripheral nerve during experimental demyelination in the cat. Neurology (Minneap.), 14, 714-726.

Mumenthaler, M. (1960). Die Ulnarislähmungen. Uber 314 'nichttraumatische' eigene Beobachtungen. Schweiz. med. Wschr., 90, 815-820.

Osborne, G. (1959). Ulnar neuritis. Postgrad. med. J., 35, 392-396.

Schubert, H. A. (1964). Conduction velocities along course of ulnar nerve. J. appl. Physiol., 19, 423-426.

Simpson, J. A. (1956). Electrical signs in the diagnosis of carpal tunnel and related syndromes. J. Neurol. Neurosurg. Psychiat., $19,275-280$.

Sunderland, S. (1965). The connective tissues of peripheral nerves. Brain, 88, 841-854.

Tascon-Alonzo, M. (1963). The Amplitude and Duration of Evoked Action Potentials in Human Hand Muscles in Health and Disease. Thesis: University of Alberta.

Vizoso, A. D. (1950). The relationship between internodal length and growth in human nerves. J. Anat. (Lond.), 84, 342-353.

Wylie, W. D., and Churchill-Davidson, H. C. (1966). A Practice of Anaesthesia, 2nd Ed., p. 1110 . Lloyd-Luke: London. 